\title{
O SISTEMA CEP/CONEP NO BRASIL: DISCURSO E REALIDADE DEZ ANOS DEPOIS
}

\author{
Juliana AT Werner \\ Maria Tereza de Campos Velho*
}

\section{RESUMO}

Este texto propõe uma análise do sistema CEP/CONEP no Brasil desde sua implementação, há 10 anos. Para tanto, foi feita uma introdução geral referente aos documentos universais que tem inspirado ideologicamente os autores do texto da resolução 196/1996. Após uma breve introdução, o presente estudo aborda o funcionamento deste sistema sua implementação e finalmente, propõe analisar os pontos positivos e negativos do sistema. $O$ sistema CEP/CONEP foi implantado no país, com eficiência e a relativa adesão da comunidade científica brasileira. Pode-se dizer que a CONEP cumpre com atribuições maiores, respeitando o que diz a resolução 196/1996 que a instrui e que, em última instância, protege os sujeitos de pesquisa. Todavia, em um sistema complexo que se implantou com rapidez permanecem falhas que precisam ser percebidas e solucionadas. Entre as questões mais críticas está a falta de capacitação de muitos membros dos CEPs que, segundo os mesmos, se encontram solitários e muitas vezes desamparados pelo sistema central (CONEP) e suas instituições de origem. Como conclusão, se pode dizer que ocorre uma centralização dos conhecimentos na área da ética na pesquisa em algumas capitais do país, o que não ocorre em CEPs de outras regiões apesar de fazerem parte de um mesmo sistema.

Palavras-chaves: Bioética. Comitê de Ética Ética em pesquisa.

\section{INTRODUÇÃO}

Este trabalho tenciona descrever a construção, a estruturação e a atuação do sistema formado pelos Comitês de Ética em Pesquisa e Comissão Nacional de Ética em Pesquisa denominado sistema CEP/CONEP. Bem como avaliar criticamente alguns dos aspectos positivos e negativos do sistema brasileiro de ética em pesquisa. Para que este objetivo possa concretizar-se, iniciamos nosso trabalho com um breve histórico das normativas regentes na pesquisa com seres humanos e histórico do sistema brasileiro de ética na pesquisa. Ao final do relato, com base em dados bibliográficos e análise dos dados desenvolvidos pelo sistema, analisamos e discutimos alguns fatores em relação ao sistema a través da resposta a pergunta que fizemos por e-mail a alguns membros e coordenadores de CEPs das regiões sul e sudeste do Brasil. As perguntas eram referentes às suas percepções quanto ao sistema CEP/CONEP, principalmente em relação ao papel educativo da CONEP. Levando em conta o que nos foi dito, foram discutidos alguns pontos - 
favoráveis e desfavoráveis - considerados importantes no que se refere ao referido sistema na atualidade.

\section{NORMATIVAS REGULAMENTADORAS}

Segundo Ferrer (2003), os comitês de ética em pesquisa são estruturas cuja atribuição essencial é "assegurar a proteção dos sujeitos de pesquisa clínica, bem como a relevância e correção dos protocolos de pesquisa que se submetem a consideração". As discussões, acerca das moralidades de pesquisas com seres humanos, vêm desde a antiguidade grega e romana, passando pelos escritos de Maimônides e Bacon (Saidón, 2007). Nos séculos $\mathrm{XVIII} \mathrm{e} \mathrm{XIX,} \mathrm{as} \mathrm{pesquisas} \mathrm{eram} \mathrm{basicamente} \mathrm{terapêuticas} \mathrm{e} \mathrm{se} \mathrm{realizavam} \mathrm{em}$ pequena escala. Em 1830 se percebeu a necessidade de introduzir alguns parâmetros éticos nas pesquisas. O médico francês Claude Bernard, em ensaio sobre o estudo da medicina, afirmou que somente seria válido realizar experimentos com humanos caso esses possam trazer algum benefício.

Na Alemanha de 1901, o Ministério de Assuntos Religiosos, Educativos e Médicos da Prússia estabeleceu a proibição de pesquisas não terapêuticas em menores e incapacitados (Capron, 1989). Durante a Segunda Guerra Mundial houve uma mescla de cuidado e arrogância nos temas que se referiam a pesquisa com humanos: cuidados por parte do Comitê de Pesquisa Médica, que avaliava se algo podia resultar em uma ação pública adversa. A arrogância estava em se fazer, em nome do bem, experimentos com seres humanos vacina para disenteria em órfãos desabrigados - causando muitos efeitos colaterais adversos. Existem, ainda, relatos de experimentos realizados neste período, onde se utilizava pessoas com retardo mental, pacientes prisioneiros ou soldados como sujeitos de pesquisa. Nos tempos de guerra, os pesquisadores consideravam que os fins justificavam os meios, motivo pelo qual, o consentimento dos participantes era considerado prescindível.

Sass (1983) relata a primeira publicação dos regulamentos relativos à Experimentação Humana, que eram obrigatórias por lei antes e durante 0 Terceiro Reich, 1931 e 1945. Ele descreve o conceito básico das orientações para proteger indivíduos e pacientes, e para incentivar a Nova Terapia e Experimentação Humana. Questões importantes, como a responsabilidade pessoal do médico ou pesquisador, o ensino da ética da pesquisa, bem como a pesquisa e tratamento em populações vulneráveis são abordadas neste documento. Esta formulação é, por vezes, comparada aos regulamentos no Código de Nuremberg e a normativas posteriores. Costuma-se dizer que 0 nascimento da bioética moderna está historicamente associado aos abusos na pesquisa científica realizados nos experimentos da época nazista. No final da Segunda Guerra Mundial, o processo de Nuremberg expôs publicamente todos os horrores a que foram submetidos os prisioneiros dos campos de concentração. Assim, o chamado Código de Nuremberg (1947) deu início a formulação de normativas mais precisas para proteger a integridade dos sujeitos humanos em pesquisas biomédicas. Os pontos principais do documento determinaram a obrigatoriedade da informação aos sujeitos de pesquisa sobre tudo o que podia suceder em decorrência da pesquisa. Isso era 
feito por meio de um consentimento informado e, ademais, Ihes esclarecia sobre o direito de deixar o estudo e/ou experimento no momento que desejassem, se assim decidissem (Ferrer, 2003; Freitas, 2006; Arostegy, 2005; Trials of war Criminal, 1949).

Ferrer (2003) enfatiza que o conceito de um comitê encarregado da revisão ética de um protocolo de pesquisa aparece, pela primeira vez, em 1953. O Nacional Institutes of Health $(\mathrm{NIH})$ dos Estados Unidos estabelece que toda a pesquisa com seres humanos deve ter a aprovação de um comitê responsável por sua proteção. Entre o fim dos anos 60 e o início dos 70, foram divulgadas e comprovadas situações abusivas que ocorriam com relativa freqüência no setor acadêmico. Isso provocou a indignação social e reação dos órgãos corporativos como a Associação Médica Mundial. Tanto que em 1964 foi elaborada outra normativa: A Declaração de Helsinque, durante a 18 Assembléia da Associação Médica Mundial (WMA). O documento passou a ser aceito como uma referência internacional acerca das questões éticas na pesquisa médica (Freitas, 2006; Ferrer, 2003; World Medical Association, 1979).

Em 1979, depois de um trabalho de aproximadamente três anos, a Comissão Nacional para a Proteção dos Sujeitos Humanos na Pesquisa Biomédica e Comportamental (National Comission for the Protection of Human Subjects of Biomedical and Behavioral Research), publicou o Informe Belmont (The Belmont Report: Ethical Principles and Guidelines for Protection of Human Subjects of Research). Esse documento se converteu em um dos textos fundamentais da bioética moderna, onde "expressa que qualquer atividade científica com sujeitos humanos, que tenha um elemento de pesquisa, requer escrutínio ético para a proteção dos mesmos" (Ferrer, 2003, p. 26). Tais declarações fundamentam-se no respeito pelas pessoas, na beneficência e na justiça. O controle das pesquisas foi definido, então, como uma avaliação prévia de protocolos de pesquisa, sobre a base de referências éticas. Isso seria feito por um grupo independente dos pesquisadores dos estudos propostos, das instituições e dos patrocinadores. Com essas medidas o objetivo era ponderar os riscos e benefícios das pesquisas e a proteção dos sujeitos de pesquisa contra possíveis danos.

O desenvolvimento da Ética na pesquisa se mesclou com a Bioética, sendo a primeira parte substancial da segunda. O termo Bioética utilizado por Potter (1971) trata de um campo do conhecimento do qual observa as relações entre as conseqüências do desenvolvimento tecnológico e a sobrevivência do ser humano, bem como do meio ambiente (Freitas, 2006; Beauchamp, 1994). Desta maneira, diferentes temas relativos à ética têm sido identificados nos processos que questionam as decisões na Bioética e ética na pesquisa.

Beauchamp e Childress (1994) escreveram a respeito das escolhas e decisões pessoais dos sujeitos de pesquisa e seus direitos de agir segundo a vontade dos mesmos; diz-se que o dever que nós temos - trabalhadores da saúde e pesquisadores - é o de ajudar e jamais causar dano a outrem (o primum non nocere da ética médica). Ademais, preconizam que os médicos, os pesquisadores e o Estado precisam atuar com equidade e fazer a distribuição justa dos cuidados de saúde, assim como balancear muito bem os riscos e 
benefícios das pesquisas. Luna (2004) reitera que os autores referidos anteriormente "desenvolveram um marco teórico para poder identificar, resolver e analisar os problemas morais que surgem no âmbito da saúde". É a chamada ética principialista (freqüentemente aplicada na América do Norte, apesar de suas limitações), a qual, segundo a autora, tem sofrido sucessivas modificações até hoje.

\section{A ESTRUTURAÇÃO DOS SISTEMAS DE REGULAÇÃO DAS PESQUISAS}

A regulação das pesquisas médicas, biomédicas e na saúde tem passado por franca evolução em muitos países. A Europa Ocidental e América do Norte são os locais que mais tem experiência no que se refere à regulamentação das pesquisas. A cooperação internacional nestes temas foi, provavelmente, o que mais contribuiu ao estabelecimento de leis e normas nos países que apóiam ou realizam projetos multicêntricos na área da saúde, em particular os que têm objetivo de testar novos medicamentos (Ferrer, 2003). Podemos dizer que atualmente, no Brasil, há maior sensibilidade moral na sociedade, o que demanda mais atenção, cuidado, divulgação e conhecimento sobre pesquisas com seres humanos. Desta forma, acompanhando o desenvolvimento mundial, o Brasil tem desenvolvido normas, em conformidade com as normativas mundiais anteriormente descritas, acerca da pesquisa com seres humanos. Por esta razão, se instituiu a Comissão Nacional de Ética na Pesquisa (CONEP), pela resolução 196/1996 do Conselho Nacional da Saúde (CNS), para atuar como um órgão de controle social que analisa os aspectos éticos de pesquisas envolvendo seres humanos. $O$ mesmo é responsável pela orientação dos profissionais e é, também, a instância final de recursos de qualquer das partes a que a ela recorram. Se atribui à CONEP a coordenação de uma rede de Comitês de Ética (CEPs), implementados nos mais diversos tipos de instituições que de algum modo trabalhem com pesquisas utilizando seres humanos, formando o Sistema CEP/CONEPCEP/CONEP. Este último é, também, um organismo consultor junto ao Ministério da Saúde e outros órgãos que constituem o Sistema Único de Saúde do país (SUS).

A CONEP tem a atribuição de analisar e avaliar projetos de pesquisa enviados pelos CEPs. Os projetos que devem seguir este procedimento são aqueles qualificados como pertencentes a áreas especiais que, elegidas por seu critério de risco, e que apresentem dilemas éticos e complexos. Entre estes projetos poderíamos citar aqueles que tratam da genética e reprodução humana, fármacos, vacinas, estudos de novos diagnósticos, medicamentos ainda não registrados no país, equipamentos, suprimentos e novos dispositivos para a saúde, assim como novos procedimentos reconhecidos na literatura, populações indígenas e projetos que tratem de biossegurança. Também compartilham do mesmo caso investigações realizadas em conjunto com instituições estrangeiras, seja no que se refere à coordenação, participação ou quando se requer o envio do material biológico ao exterior. Ainda, passam pela averiguação da CONEP projetos que, sobre bases justificadas pelos CEPs, devam submeter-se a análise dessa comissão. 
O documento da CONEP foi elaborado por pessoas versadas em bioética e ética da pesquisa que têm, em sua origem ideológica e teórica, uma diversidade de fundamentos que Ihes serviram como base. No princípio da resolução são citados e mencionados os códigos legais que thes deram substrato para sua formulação: O Código de Nuremberg (1947), a Declaração Universal dos Direitos Humanos (1948), a Declaração de Helsinque (1964 e suas versões posteriores: 1975, 1983, 1989), o Pacto Internacional sobre os Direitos Civis e Políticos da ONU (1966), as Propostas de Diretrizes Éticas Internacionais para Investigações Biomédicas que envolvam seres humanos (CIOMS/OMS, 1982, 1993) e as Diretrizes Internacionais para as revisões Éticas dos Estudos Epidemiológicos (CIOMS, 1991). Os especialistas que formularam o código da CONEP levaram em conta, ainda, a Constituição Brasileira (1988) e suas legislações conjuntas que são o Código do Consumidor, os Códigos Civil e Penal e o Estatuto dos Direitos da Criança e Adolescentes (ECA) e outras leis que regulam os temas relativos à saúde e pesquisa no país (Di Napoli, 2007; CEF/88; ECA). A publicação desta resolução foi um marco sumariamente importante na regulamentação da pesquisa com seres humanos no Brasil, e em um contexto mais amplo, teve grande importância no desenvolvimento e estudo da Bioética que, entretanto, permanece como um processo inicial que se desenvolve lentamente. ${ }^{1} \mathrm{O}$ sistema CEP/CONEPCEP/CONEP funciona com o apoio do Conselho Nacional de Saúde (CNS) e Ministério da Saúde do Brasil.

No documento final se afirma que a CONEP é um órgão colegiado, de natureza consultiva, deliberativa, normativa, educativa e independente. Deve ser composto de forma multi e transdisciplinar, com pessoas de ambos os sexos e ser composta por treze membros titulares e seus respectivos suplentes. Cinco membros devem ser pessoas com destacada atuação no campo da ética em pesquisa e na saúde, os oito restantes são pessoas com atuação relevante nos campos teológico, jurídico e outros. Um destes, pelo menos, deve ter formação em gestão de saúde. Os membros são selecionados a partir de listas indicativas elaboradas pelas instituições as quais os CEPs se vinculam, com registro na CONEP, sendo que sete membros são eleitos pelo Conselho Nacional de Saúde, e seis são definidos por sorteio. Também podem participar da comissão consultores e membros ad hoc e além de um representante dos usuários (Resolução 196/1996).

A resolução 196/1996, que se atribui a CONEP, se declara como órgão responsável pela análise de aspectos éticos de pesquisas com seres humanos e, quando necessário, a atualização das normas que abarcam estes temas. Também são funções da Comissão: estimular a criação de CEPs institucionais; promover o registro dos mesmos; aprovar em um prazo de 60 dias e acompanhar os protocolos de pesquisa em áreas temáticas especiais; prover normas específicas no campo da ética na pesquisa, inclusive as temáticas especiais, bem como recomendações para sua aplicação; funcionar como instância final de recursos, em caráter ex - oficio ou a partir de denúncias ou solicitação das partes interessadas; revisar responsabilidades, proibir ou interromper a pesquisa de maneira temporária ou definitiva; integrar um sistema de informação e acompanhamento dos aspectos éticos das pesquisas que envolvam seres humanos no Brasil, mantendo atualizado seu banco de 
dados (o atual sistema SISNEP, já em atividade); informar e assessorar o MS, - CNS, o SUS bem como instâncias do governo e da sociedade sobre as questões que estão a cargo de sua gestão; divulgar as normas mundiais e da CONEP que envolvem a pesquisa com seres humanos; estabelecer normas e critérios para formação de novos centros de pesquisa e, por fim, estabelecer suas normas para o desenvolvimento das atividades (Resolução 196/1996).

O documento inicial tem sete resoluções complementares a primeira: 1997 (com temas sobre novos fármacos, vacinas e testes diagnósticos); 1999 (para protocolos de pesquisa com cooperação estrangeira); 2000 (para reprodução humana); 2000 (para pesquisa com populações indígenas); 2004 (para pesquisas com genética humana); 2005 (para projetos multinacionais do grupo l); 2005 (para projetos que incluem armazenamento ou utilização de materiais biológicos ou formação de bancos de materiais) (Resoluções CNS 251/97, 292/99, 303/00, 304/04, 340/04, 346/05, 347/05). ${ }^{2}$

Os CEPs iniciaram suas atividades em várias instituições no Brasil no ano de 1997. São instâncias multidisciplinares, independentes dos patrocinadores, dos pesquisadores, da direção da instituição e cumprem o compromisso de amparar os sujeitos de pesquisa em nome da sociedade e de modo independente (munus publico), ao analisar e qualificar de maneira ética os projetos. Desta forma são responsáveis junto ao pesquisador (cuja responsabilidade é indelegável e intransferível), à instituição e aos patrocinadores, em assegurar o respeito e os direitos dos sujeitos da pesquisa, com finalidade de construir uma cultura de reflexão ética entre todas as partes do projeto (Freitas. 2006; Di Napoli, 2007; Resolução 196/1996).

Ao final do ano de 2005, a CONEP registrou 448 CEPs, entre 650 solicitações, no país. Os projetos aprovados cumpriam as exigências da Comissão Nacional (Di Napoli, 2007). Um CEP é composto por aproximadamente 11 membros, portanto teríamos nesse período, quase 5000 pessoas participando de diferentes tarefas nos comitês, trabalhando com objetivo de preservar e assegurar os direitos dos sujeitos de pesquisa (Di Napoli, 2007). Aos membros da CONEP se exige ainda mais conhecimento das questões éticas referentes a pesquisa, bioética e metodologia da pesquisa. Um dos problemas mencionados a seguir, no presente trabalho, está relacionado à deficiência da formação de temas de ética na pesquisa com seres humanos, pelos membros dos comitês, com exceção de alguns profissionais já capacitados para o exercício destas funções (Di Napoli, 2007, Freitas, 2006).

O sistema CEP/CONEP é igualmente responsável pela implementação do projeto e, se ocorrer alguma irregularidade, pode solicitar a suspensão temporária ou definitiva do mesmo. Os membros dos CEPs deveriam, segundo as diretrizes da CONEP, ser pessoas capacitadas em pesquisa e com 0 mínimo de conhecimento em Bioética. Segundo as regras da CONEP é oportuno e necessário que se mantenha a equidade de gênero entre os membros dos CEPs.

A idéia geral, como afirma Lins, citada por Freitas (2006), é que "os CEPs não dever ser tidos como tribunais reacionais desta ou daquela linha de bioética hegemônica, mas devem ser verdadeiros laboratórios de discussões 
ético-políticas das ciências tecnológicas emergentes [...] o comitê vive e experimenta o caso". Freitas (2006) que verificou o perfil dos membros dos CEPs e também outros temas referentes aos comitês, observou ainda que, geralmente estes são formados por pessoas de ambos os sexos, das mais variadas profissões, mas em sua maioria os comitês são compostos por pessoas da classe médica. Os pesquisadores são provenientes de diversas áreas do conhecimento, com destaque à pesquisa clínica. Em vários comitês havia, segundo resultados obtidos pela autora, representantes dos usuários. Isto representa um dado de suma importância, pois sabemos a dificuldade que existe na escolha de pessoas que, sem impedimentos, sejam capacitadas para exercer esta função.

O sistema CEP/CONEP se estruturou muito rápido no país, sendo esta estrutura de funcionamento relativamente sensível. A respeito do funcionamento dos CEPs institucionais é possível mencionar que estruturalmente agem da seguinte forma: primariamente, recebem os protocolos que devem ser analisados. Aqueles projetos que não estejam incluídos no grupo de temáticas especiais e que sejam aprovados podem ter início. No caso de haver correções e/ou sugestões, os projetos retornam ao pesquisador para sua adequação e então retorna ao CEP para nova avaliação. Cumpridas as exigências, o mesmo é então, aprovado. Quando o projeto trata de questões especiais de pesquisa, se faz necessária a avaliação da CONEP, que tem 60 dias para analisar o projeto e, se aprovado, comunicar ao CEP local, que repassa ao pesquisador a autorização para iniciar o projeto proposto. $\mathrm{Em}$ casos que requeiram alterações, se comunica ao pesquisador, que deve atender as pendências apontadas e adequar o projeto. Logo que se corrijam as pendências, e que a CONEP faça seu parecer favorável, o pesquisador principal, depois de informado, está autorizado a iniciar o trabalho de pesquisa.

Atualmente, no Brasil, o sistema CEP/CONEP está totalmente integrado pela rede. A CONEP tem o controle e a informação atualizada dos CEPs, bem como de todos os projetos e pesquisadores registrados. Esses, por sua vez, fazem um registro on-line, diretamente no sistema, e após registrarem-se como pesquisadores recebem uma senha. $O$ projeto recebe um número nacional (CAE) e é gerada uma folha de rosto (onde se encontram dados sobre 0 pesquisador, a instituição e título do projeto). Essa folha é incluída no protocolo de pesquisa que será encaminhado ao CEP, com toda a documentação necessária anexada ao projeto de pesquisa. Este sistema integrado se chama SISNEP (Sistema Nacional de Informações em Pesquisa), e forma a base de dados da CONEP. O órgão exerce desse modo sua função de gerar um registro geral e possibilita a busca e o controle sobre as pesquisas que são realizadas no país, bem como o pretendido controle sobre as mesmas, pois estes dados estão ao alcance de qualquer pessoa que consulte o sistema. ${ }^{3}$

Pode-se dizer então que é um sistema que foi criado recentemente e que recebeu a pronta adesão da comunidade científica do país, cumprindo com uma importante função de controle científico, ético e social nas pesquisas com seres humanos em um país onde, assim como tantos outros, se denunciam abusos indecorosos nesta área. O papel da CONEP, nessa situação, é muito eficiente. Freitas (2006) enfatiza que o Brasil é um dos países ausentes nas notas da imprensa internacional que mencionavam a completa falta de normas 
e estruturas de controle social sobre as pesquisas com humanos, denunciando exploração de populações mais vulneráveis. Isso revela, apesar dos muitos problemas que ainda existem, que houve melhoras substanciais e algo de promissor em todo o importante e sério dever que têm os órgãos responsáveis pelo cuidado com os sujeitos de pesquisa. Mas ainda existem problemas? Quais? Isto será discutido no tópico que segue.

\section{ANÁLISES DO SISTEMA CEP/CONEP}

O sistema CEP/CONEP existe e atua há aproximadamente oito anos. Durante este período pode-se dizer que houve grande adesão ao programa por parte da comunidade científica que utiliza seres humanos como sujeitos de pesquisa. O que foi observado pelo empenho na criação dos CEPs nas instituições que abarcam este tipo de pesquisa. Portanto é possível afirmar que os primeiros passos e tentativas da CONEP resultaram na mobilização dos pesquisadores e promoveu uma disseminação da cultura e das normas internacionais que regem as questões relacionadas à pesquisa com seres humanos. Em função desta implementação, passamos de um período de total desregramento a outro mais claro, democrático e protetor dos sujeitos de pesquisa que corresponde às normativas mundiais acerca do tema. Em um curto período de tempo, as informações foram disseminadas por todo 0 território brasileiro ainda que com um grande atraso em relação a países mais desenvolvidos, ou outras com histórico na ética da pesquisa, como a Argentina por exemplo. Aqui as coisas começaram mais tarde, mesmo já tendo sido promulgada a Declaração de Helsinque. No Brasil ainda era costumeiro e corrente algumas atitudes que já não eram adotadas, e eram até mesmo proibidas, em países que já consideravam a Declaração de Helsinque. Dois principais fatores que tornaram mais difícil a implementação ou não resolução dos problemas na pesquisa com seres humanos: o sistema econômico dos países e suas prioridades de inversões, ou seja, a cultura que de forma geral é adotada por países que não priorizam o auxílio mais concreto aos órgãos reguladores das pesquisas.

Sob estas condições podemos dizer que, no Brasil, esse panorama tem sido modificado substancialmente apesar de ainda não o suficiente. Todavia ainda observamos problemas de pesquisa relevantes, que precisam ser sanados. O papel da CONEP tem se cumprido de modo muito satisfatório em diversos pontos. Entretanto, permanecem falhas importantes. A divulgação da cultura da ética em pesquisa, a formação de um banco de dados completo e atualizado que informe sobre o processo de pesquisa no Brasil e que possa ser acessado por qualquer pessoa - expondo ao controle social os projetos que se desenvolvem (no Sistema SISNEP) - tiveram resultados satisfatórios e é algo bastante elogiável. Por todo este processo os abusos nas pesquisas envolvendo seres humanos diminuíram substancialmente em um curto período de tempo.

Modificar uma estrutura até então imutável, não é uma tarefa fácil. Há um longo caminho a percorrer. Por isso, quais são as inquietações? O que não está em conformidade com todo esse progresso? 
Para tentar responder a estas questões, perguntamos a alguns coordenadores e membros de CEPs no Brasil, acerca do papel da CONEP, principalmente sua função educativa e de supervisão dos CEPs. A pesquisa se desenvolveu em quatro diferentes estados (os quais não serão revelados, preservando sua privacidade) por e-mail, e foi solicitado que os membros avaliassem o sistema CEP/CONEP quanto ao seu funcionamento, bem como seus pontos positivos e negativos sobre as questões formuladas.

As respostas coincidem em várias assertivas. Considerando o papel educativo ao que se propõe a CONEP, se pode afirmar que sua execução está longe de alcançar uma marca que seja razoável. É uma reclamação geral a de que os comitês estão solitários. Isso de pode indicar pelas falas abaixo descritas:

\footnotetext{
Se pode dizer que a situação tem melhorado muito. Mas o papel que se impõe à CONEP de educar, supervisar, não é percebido. Nós estudamos e tentamos conduzir as coisas da melhor maneira possível, mas nos falta. (A).

Nunca alguém da CONEP esteve aqui. Lhes envio os relatórios do CEP. Apenas tem nos apoiado por enviar material, cds e livros [...] Estudamos por nossa conta. Nos falta conversas e discussões. Estamos sozinhos. O sistema foi implementado, mas estamos sozinhos $[\ldots](B)$

Muitas vezes nos sentimos inseguros. Existem assuntos dos quais não sabemos. Tentamos resolvê-los da melhor maneira possível. Porém, nos falta uma capacitação formal, que não apenas por livros $[\ldots](C)$.
}

De acordo com a resolução, é necessário que os membros de comitês tenham alguma formação em ética da pesquisa, e/ou bioética, e/ou metodologia da pesquisa. Entretanto, na realidade, não é o que acontece. Podemos afirmar que em algumas capitais as equipes têm melhor formação e há comitês muito bem preparados. São exemplos citados por Freitas (2006) e com os quais concordamos, os comitês do Hospital de Clínicas de Porto Alegre (RS), e o da PUC- PoA, Pontifícia Universidade Católica de Porto Alegre (RS), o comitê da USP (Universidade de São Paulo), entre outros. Verificamos assim, uma centralização importante na constituição do saber - o que também ocorre se considerarmos outros temas relacionados às universidades no Brasil.

Porque isso tem ocorrido? Os comitês que surgiram, para atender a obrigatoriedade da resolução, pertencentes a instituições mais distantes das capitais, foram constituídos de maneira precária. Ainda que seus membros tenham um alto grau de formação acadêmica, não tem formação específica em ética aplicada a pesquisa, metodologia da pesquisa clínica bem como outros requisitos considerados imprescindíveis para a análise de qualquer projeto que Ihes seja repassado. Sobre esse tema Luna (1994) alerta que muitos comitês de ética podem começar com muito entusiasmo, mas pouca formação: "Por isso de pode denegrir e anular a possibilidade de criar um bom comitê por não poder lidar com determinadas situações, por não saber quais são os casos mais relevantes eticamente e quais não o são".

Por tanto é importante que os órgãos que impuseram a formação de tais comitês, devem ter como premissa básica, a formação adequada das pessoas 
que vão constituir estes comitês. Para isso deveriam ser organizadas oficinas, palestras, debates, além de convidar especialistas a fim de trocar idéias e experiências. Luna (1994) enfatiza: "um Comitê de Ética deve estar preparado para sua tarefa. O Comitê não pode pretender instruir à (sic) outros se o mesmo não é devidamente instruído". É necessário levar em conta que, segundo a autora, um bom Comitê de Ética melhora e assegura a boa imagem da instituição, contribuindo com o crescimento e atuação da mesma.

A CONEP disponibiliza livros, bem como material informatizado para a capacitação dos membros dos comitês. No entanto, este suporte não é considerado suficiente. Há falta de discussão e de permuta ou troca de idéias com especialistas no tema. As situações são múltiplas, diversas e particulares. Isso torna o trabalho mais difícil de ser feito, e os questionamentos dos pesquisadores não são devidamente sanados.

Deve se discutir constantemente com profissionais que tenham mais experiência e que, mais prontamente, possam contribuir com questionamentos específicos. Pode-se dizer que o sistema CEP/CONEP, cresceu de cima para baixo. De acordo com coordenadores e membros dos CEPs lhes falta suporte, do sistema central, a CONEP e, na maioria das vezes, da própria instituição a qual estão vinculados. Estes relatos são corroborados por Freitas (2006) para interpretar as pesquisas sobre as condições do CEPS brasileiros. Por um lado, há reclamações muito consistentes, que se repetem em vários países latinoamericanos (Freitas, 2006; Luna, 2002) que os membros do comitê fazem um esforço árduo para conquistar o respeito de seus colegas. Em muitos lugares, ainda são considerados como "juízes de tribunais" e pessoas que obstruem o processo de pesquisa com burocracias impertinentes. Isso implica em um esforço constante de conscientizar a comunidade acadêmica - em toda sua formação docente e discente - da importância dos comitês em sua tarefa primária de assegurar a proteção e respeito aos sujeitos de pesquisa. Sabemos a importância que tem para uma instituição a presença de um comitê de ética enquanto bons representantes da comunidade científica e da sociedade.

Em contrapartida, os membros de comitês devem estar preparados e com boas bases de conhecimento, tanto em questões pontuais, que a estes cabe dominar, bem como estar conscientes das mudanças culturais, em qualquer campo da vida ou do conhecimento, que tendem a ocorrer. Às vezes são formadores e a formação ou informação permanente é parte de seu papel educador. Os profissionais que participaram da pesquisa afirmam que freqüentemente tentam cumprir esta função, mas sentem a falta, quase total, de suporte por parte da CONEP. Sentem-se solitários e afirmam "que se instituiu um sistema, mas não Ihes é dado as condições de cumprirem com suas prerrogativas". Além disso, este é um trabalho voluntário, que se efetua além das demais tarefas realizadas pelas participantes dos CEPs, que em geral, são professores universitários. Essa é a realidade em muitos países da América Latina no que diz respeito, principalmente, aos comitês de órgão ou instituições públicas. Não se discute aqui, neste ponto, a situação de comitês de ética de instituições privadas, que em geral recebem por seu trabalho. A remuneração dos membros dos CEPs é certamente uma questão polêmica e controversa. Isso é corroborado por Freitas (2003), quando analisa esta problemática no Brasil, e Luna (2004) que faz um comparativo dos comitês de 
ética norte-americanos com os comitês argentinos. Há algo mais em comum nos países da América Latina, além de suas condições econômicas, problemas de pobreza, desigualdade social, educacional e violência.

Corroboramos estas prerrogativas afirmando que as instituições as quais se vinculam os CEPs, segundo alguns de seus membros, também não lhes dão a importância necessária. $O$ que se percebe pelo espaço físico dos escritórios, que é muitas vezes, inadequado, pela falta de funcionários permanentes e treinados para as funções que precisam exercer a fim de contribuir com o trabalho dos membros dos CEPs; o orçamento destinado ao material permanente é pouco ou nenhum (no princípio da formação dos CEPs, a CONEP ofereceu subsídios para a compra de computadores e material necessário para o funcionamento dos comitês, mas não é um comportamento rotineiro). Tampouco há o necessário aporte financeiro para realização ou participação de oficinas de capacitação, jornadas ou congressos. Sendo assim, a formação dos membros habitualmente se dá por iniciativa própria, ou por meio de discussões que eventualmente surgem pela analise de projetos de pesquisa. Essas práticas podem gerar conhecimento, mas de modo lento e por vezes incompleto, permanecendo falhas e dúvidas. É necessário que as instituições sejam mais comprometidas, principalmente as universidades, em respeito e apoio real aos CEPs, que podem constituir uma melhoria da imagem desta enquanto instituição preocupada com a construção do saber e com a comunidade da qual faz parte. Quanto à supervisão dos CEPs pela CONEP há quem diga que esta é muito precária. Em relatório da CONEP (Relatório do Sistema CEP/CONEP, 2005), se afirma que em muitos comitês não chegaram solicitações de informações acerca de seu funcionamento, de como estão ou se algo Ihes falta, nem por questionários, ou solicitações de visitas de alguém da equipe da CONEP. Os coordenadores, em sua maioria, dizem que não receberam visitas de representantes da CONEP, nem tampouco vistoria ocasional, portanto não se sabe como é feita a supervisão in loco. As informações as quais tem acesso a CONEP são obtidas, em geral, pelo sistema SISNEP.

Outra observação pontual feita por alguns membros dos CEPs, em conformidade com a afirmação de Di Napoli (2007) e com a qual também concordamos, é que a CONEP tem em suas normativas, temas e modos de pensar que tem foco quase exclusivo nas pesquisas de áreas biomédicas, conservando a hegemonia do modelo biomédico. Quase não há alusão às especificidades de temas mais singulares, como aqueles de pesquisas qualitativas muito presentes nas áreas relacionadas às ciências sociais que, por certo, também tem nos seres humanos, seu foco de pesquisa e interesse. Seria importante considerar estes temas e seguir este movimento e ramo do saber constituído a ser criado buscando a especificidade deste modo de pesquisa que, declaramos, é um campo muito amplo do saber e das pesquisas no Brasil. Devemos ter um olhar especial e, no momento, voltado a este tipo de pesquisa, e ter claro que o modelo biomédico de pesquisa, não constitui 0 único modelo de pesquisa. ${ }^{4}$ 


\section{CONCLUSÃO}

Após nossa breve exposição, é possível afirmar que se tem implementado com relativa rapidez e eficácia o sistema regulatório acerca da pesquisa envolvendo seres humanos no Brasil. É um sistema reconhecido por sua boa sistemática de operar, assistir, conduzir e, geralmente, orientar. À esse rapidamente aderiram toda a comunidade científica e instituições brasileiras. Porém, em um sistema que se implanta de forma acelerada e recebe tantas adesões, pode desenvolver-se com muitas falhas, principalmente quando se trata de um país em desenvolvimento e com um grande território geográfico, o que pode dificultar a implementação. A introdução do sistema CEP/CONEP e a organização dos profissionais têm gerado uma nova cultura e um novo modo de pensar e discutir as questões acerca da pesquisa com seres humanos. Estamos conscientes de que uma nova etapa foi estabelecida e que muito já foi feito. Mas ainda há muitos caminhos inacabados que precisam ser revistos e aprimorados. As divergências na relação entre CEP/CONEP ocorrem porque os primeiros (CEPs), muitas vezes, parecem estar sozinhos no que corresponde a sua capacitação. Falta o apoio e verba da CONEP e das instituições as quais os CEPs estão vinculados. Seus membros precisam, antes de tudo, ter capacitação para que possam desempenar suas funções da melhor maneira possível, trabalhando em prol da imagem de suas instituições, e em última instância, cumprindo com o propósito maior de proteger e assegurar adequadamente os direitos dos seres humanos que participam como sujeitos de pesquisa.

\section{THE SYSTEM CEP/CONEP IN BRAZIL: SPEECH AND REALITY TEN YEARS AFTER}

\section{ABSTRACT}

The aim of this paper is analyze the system CEP/CONEP in Brazil since its implementation, 10 years ago. To that end, there was a general introduction to concerning universal documents which has ideologically inspired the authors of the text of resolution 196/1996. After a brief introduction, this study addresses this system implementation and finally, proposes to analyze its strengths and weaknesses. The system CEP/CONEP was efficiently implanted in the country, with considerable adherence of membership of the Brazilian scientific community. Can be said that CONEP has major powers, respecting what the resolution 196/1996 declares, which ultimately protects the subjects of research. However, in a complex system that was quickly implanted remain mistakes that must be understood and resolved. As example of the most critical issues is the lack of training of many members of the CEPs, which are lonely and often unhelped by the central system (CONEP) and its institutions of origin. In conclusion, we can say there is a centralization of knowledge in ethics 
research in some metropolitan centers, what does not occurs on CEP from other regions in spite of being part of the same system.

Keywords: Bioethics. Ethics in research. The Ethics Committee.

\section{NOTAS}

Mestre em Farmacologia (UFSM)

julywerner@yahoo.com.br

* Doutora em Enfermagem - Bioética (UFSC) e Professora Adjunta (UFSM)

mtcamposvelho@hotmail.com

1 A disciplina de Bioética, nos currículos das escolas de Medicina no país, nos cursos de graduação, veio a ser obrigatória há apenas três anos. Antes disso, o ensino na bioética, normalmente, era ofertado apenas a cursos de pós-graduação.

2 Existe um projeto de lei do deputado Colbert Martins (2003) que objetiva ou propõe a transformação da resolução 196/1996 na lei que dispõe sobre todas as diretrizes e normas que regulam a pesquisa que incluam seres humanos no Brasil. Este projeto descreve todas as atribuições da CONEP e dos CEPs, inclusive determinando questões penais agregadas a isto. Por exemplo: constitui crime expor a vida ou a saúde do sujeito de pesquisa por perigo direto ou indireto ou iminente, além dos riscos previstos na pesquisa. A pena de detenção seria de 6 (seis) meses a 3 (três) anos, se não constituir crime mais grave. É um projeto de lei que, como foi dito, não recebeu ainda sua aprovação. Mas existe e aguarda os trâmites legais que, em geral, são muito demorados e quando as questões são consideradas prioritárias pelo Congresso Nacional, sua análise já esta ultrapassada.

3 Existe uma observação com relação a essa questão que foi levantada por uma pesquisadora chilena no Seminário de Ética em Pesquisa promovido pela Fundação Fogarty e FLACSO (Faculdade Latino Americana de Ciências Sociais) na Argentina, em maio de 2007. A pesquisadora questionou o caso da confidencialidade dos projetos. Pergunta: Como estariam protegidos os pesquisadores em um sistema de registro aberto a todas as pessoas? Existem Projetos que pretendem patentes, por exemplo. Como seriam solucionados tais casos? Parece que a CONEP tem feito modificações na inscrição, protegendo o sigilo dos projetos que assim necessitem.

4 Existe um aspecto da resolução 196/1996, que fala a respeito de pesquisas onde, muitas vezes, o consentimento livre e esclarecido tem um uso específico ou distinto, como nas áreas da psicologia ou ciências sociais. Diz-se que aos CEPs, cabe a prerrogativa de julgar se os sujeitos de pesquisa podem se dar conta, as vezes, sem saber, que são sujeitos de pesquisa ( por exemplo pesquisas observacionais). Agregamos a isto o que Ruth Macklin (1987), ao referir-se a estas situações, disse que "observar aos sujeitos de pesquisa sem sua autorização ou conhecimento considera invasão do direito e privacidade de sujeito". Mas, em uma fala pessoas, no Seminário de Ética na Pesquisa de Buenos Aires, em maio de 2007, foi dito que sim, se pode observar sem o consentimento, mas que antes disso, de alguma maneira e em algum momento, se deve fazer saber a essa pessoa que ela será observada enquanto um sujeito de pesquisa. Não ficou claro, apenas, em que momento isto deve ser feito.

\section{REFERÊNCIAS}

Angell, M. The ethics of clinical research in the third World. The New England Journal of Medicine.1997; (337). 
Arostegy, J. Daño, investigación y justicia global. Perspectivas Bioéticas. 2005.

Beauchamp, TL; Childress, J. Principles of biomedical ethics. New York: Oxford University Press. 1994.

BRASIL. Constituição da República Federativa do Brasil: 1988. 21 ed. Brasília: Câmara dos Deputados, Coordenação de Publicações, 2003.

BRASIL. ESTATUTO DA CRIANÇA E DO ADOLESCENTE (1990). Lei $\mathrm{n}$. 8.069, de 13 de julho de 1990.

BRASIL. RESOLUÇÃO 196/1996.

www.conselho.saude.gov.br/docs/Resolucoes/Res0196.doc.

Capron AM. Human Experimentation. In: Veatch R. Medical Ethics. Boston: Jones and Bartlett, 1989.

CIOMS, International Ethical Guidelines for Biomedical Research Involving Human Subjects (1991) www.cioms.ch/frame 1991 texts of guidelines.htm

CIOMS. International Ethical Guidelines for Biomedical Research Involving Human Subjects. Disponível em: http://cioms//A:Iguidelines nov 2002 blurb.htm. Acesso em: 10/05/2007.

CIOMS. International Ethical Guidelines for Biomedical Research Involving Human Subjects

www.cioms.ch/frame guidelines nov 2002.htm

(1982,

1993)

Der Minister der geistlichen. Anweisung an die Vorsteher der Kliniken, Polikliniken under sinstigen Krankenanstakten. Centralblatt der gesamten Unterrichtsverwaltung in Preussen. Berlin: prussian Government, 1901.

Di Napoli, R. Fundamentos éticos e Bioéticos das resoluções sobre a ética em pesquisa no Brasil. Revista Ethic@. 2007.

Ferrer, J.J. Historia y fundamentos de los comités de ética. In: J.J. Ferrer, F. Abel, D. Gracia, J.C. Alvarez, P. Simon, I. Galende, C. Alonso Bedate, P. Núñez, organizadores. Comitês de Bioética. Editorial Descée De Brouwer, S.A., 2003.

Freitas, C. B. D. O sistema de avaliação da ética em pesquisa no Brasil: estudo dos conhecimentos e práticas de lideranças de Comitês de Ética em Pesquisa. São Paulo. São Paulo. 2006. 157f. Tese (Doutorado em Ciências, Medicina Preventiva). Faculdade de Medicina da Universidade de São Paulo.

Luna, F. Comités de ética de investigación: una comparación crítica entre Argentina y EE.UU. Journal de bioétithque. 2004.

Luna, F. Comités de Ética de Investigación: Y por casa cómo andamos? Brasília: FLACEIS, 2002.

Luna, F. Comités de Ética: un nuevo desafío para nuestra medicina. Asociación Ibérica Argentina, 1994.

National Commission for the Protection of Human Subjects of Biomedical and Behavioral research: 1979, The Belmont Report: DHEW Publication N. OS 78-0014. 
ONU. Declaração Universal dos Direitos Humanos. http://www.onubrasil.org.br/documentos direitoshumanos.php acessado dia 10/10/08.

PACTO INTERNACIONAL DOS DIREITOS CIVIS E POLÍTICOS (1966) Adotado pela Resolução n. 2.200 A (XXI) da Assembléia Geral das Nações Unidas, em 16 de dezembro de 1966 e ratificado pelo Brasil em 24 de janeiro de 1992. www.article19.org/work/regions/latin-america/FOl/pdf/onupacto inter.dir.civ.pol.pdf.

Potter V. R. Bioethics. Bridge to the future. Englewood Cliffs: Prentice Hall, 1971:2.

Saidón, P. Comitês de Ética da Pesquisa: recursos para seu melhor funcionamento. Apostila do Curso virtual de Introdução à Etica da Pesquisa. Classe 3. Maio, 2007.

TRIALS OF WAR CRIMINAL BEFORE THE NUREMBERG MILITARY TRIBUNALS. Control Council Law 1949.

Varmus, H.; Satcher, D. Ethical complexities of conducting research in developing countries. The New England Journal of Medicine. 1997; (337): 1003-1005.

World Medical Association. The Declaration of Helsink. For the Protection of Human Subjects of Biomedical and Behavioral research: 1979, Disponível em http://www.wma.net.

Recebido para publicação 30/10/2008

Aceito para publicação 14/01/2009 